\title{
Does Fintech Help to Improve the Private Enterprises Financing Situation?_ Evidence from the Chinese Market
}

\author{
Man Zhu ${ }^{1} \&$ Xingyu Jiang ${ }^{2}$ \\ ${ }^{1}$ Honors College, Nanjing Normal University, Nanjing, China \\ ${ }^{2}$ School of Business, Nanjing Normal University, Nanjing, China \\ Correspondence: Man Zhu, Honors College, Nanjing Normal University, Nanjing, China. Mobile Phone: \\ 15601592716 E-mail: man.zhu-judy@qq.com
}

Received: February 22, 2019

doi:10.5539/ijbm.v14n5p98

\begin{abstract}
Financing difficulties have plagued private enterprises for a long time. Emerging Fintech is expected to improve private enterprises' financing situation by enhancing the risk control in bank loans. This paper constructs the Fintech Policy Index and the Fintech index by text quantitative analysis and factor analysis method respectively. It selects the data of 96 private enterprises in China from 2010 to 2017 as samples, using Time-Varying Parameter State Space Model to explore how Fintech affect private enterprises' financing situation. The research shows that the elasticity coefficient of Fintech and private enterprises' financing development develops as W-type and has obvious stage characteristics. At present, the elasticity coefficient of China's Fintech and private enterprise financing is in the upward trend of W-type. Fintech is helping the private enterprises' financing, which is gradually to be realized.
\end{abstract}

Keywords: private enterprises' financing, elastic coefficient, text quantitative analysis, factor analysis, Time-Varying Parameter state-space model

\section{Introduction}

Under the economic background of de-leveraging, the problem of financing difficulties for private enterprises has become more conspicuous since 2018 in China. As far as bank lending channel is concerned, a considerable number of private enterprises could only raise limited funds due to their own size restrictions. Wen Xuezhou (2018) pointed that large banks are more inclined to lend to businesses that could provide adequate collateral, while private enterprises usually lack suitable collateral, so the funds raised by private enterprises in banks is often less than one year. Mr. Cheung Wai-li (2018) pointed that because the private enterprises' decisions are not transparent, the bank believes that lending to private enterprises is too risky. With the development of Internet Finance, more and more SMEs have begun to use Internet Finance as a new financing method to raise funds for enterprise development. Many scholars believe that the Internet has challenged the traditional financial financing structure and improved the financing efficiency of enterprises. Mishkin (1999) pointed that Internet had greatly improved the information asymmetry and widened the financing channels of enterprises. As technological advances reduce transaction costs, more financial intermediaries could obtain funds from investors, and enterprises could finance through different financial intermediaries. But the introduction of technology also brought great challenges to financial regulation. There are hidden concerns behind the rapid financing of Internet Finance. More specifically, due to the lack of regulatory entities, P2P network lending will cause private enterprises to fall into the trap of money laundering and illegal fund-raising. In addition, Li Jun (2015) pointed out that the management fee of P2P network platform had pushed up the financing cost of private enterprises. After entering 2016, Internet Finance has matured and introduced a broader concept - Fintech. The introduction of comprehensive supervision of Fintech provides a new solution to the problem of financing difficulties for private enterprises.

In the study of the difficulty of financing private enterprises, Hu Juanhui (2018) said that this was mainly due to the small scale of private enterprises, opaque internal information and other reasons, it was difficult to meet the

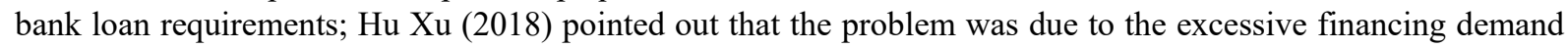
of state-owned enterprises and local governments, which had a crowding out effect on private enterprise financing. In addition, Mr Tsang (2018) proposed that the current low proportion of private enterprise borrowing 
was related to the expansion of Internet Finance and shadow banking in previous years. The lack of Internet financial credit system and inadequate supervision of shadow banking had made the asset quality of private enterprises worse. At this point, bank lending will inevitably be more cautious. Wu Yuxiang (2018) pointed out that the governance of shadow banking would narrow the financing channels of private enterprises and SMEs, which would worsen the difficulty of financing private enterprises. Fintech has recently become a new angle of view to solve the financing difficulties of private enterprises. Wang Manman (2017) pointed out that banks should use Fintech to improve the accuracy of lending. Hu Xu (2018) pointed out that qualitative and accurate assessment of the internal capital chain needs of state-owned enterprises by means of Fintech was more conducive to resolving the problem of financing difficulties for private enterprises. And Zhao $\mathrm{He}$ (2016) proposed that the core competitiveness of Fintech was more effective financing. By introducing Fintech to its risk-control process, the banking industry could leverage its account capital and risk management advantages, which made the bank's internal information to the loan company clearer. At the same time, it pointed out that Fintech could enable non-bank financial institutions to innovate traditional financial financing models, so that financing services could truly penetrate private enterprises. Dai Xiangyun (2014) proposed the model of "park + credit guarantee + government discount" as a technology financial service platform to alleviate the financing difficulties of SMEs in Nanning, but this model could not be extended to other regions. Additionally, Wang Lihui (2017) analyzed from the perspective of game theory and proposes that Fintech could solve the problem of information asymmetry in the financing process of SMEs. However, this conclusion is limited to the analysis of two financing methods of P2P financing and crowd-funding financing; in addition, the article has formulated the premise hypothesis of macroeconomic stable operation, which is not conducive to the study of the impact of Fintech on private enterprises' financing in specific periods and lacks practical help for the government's introduction of policies.

It could be seen from the above literature that the existing research mainly focuses on the qualitative analysis of Fintech for private enterprises' financing. In the existing quantitative analysis, most of the literature ends with constructing a static model to measure the relationship between the two and lacks a phase relationship between the two in different years. Based on this, this paper chooses the State Space Model with Time-Varying Parameter characteristics, and dynamically measures the impact of Fintech development on China's national enterprises.

\section{Method}

From the perspective of Fintech, this paper constructs the Fintech policy index FPI and the Fintech index FI by factor analysis and text quantitative analysis and establishes the variable parameter space state model to the elastic coefficient. It is estimated that the empirical analysis of the impact of Fintech on the financing development of private enterprises in China.

\subsection{Construct Index of FPI}

This paper draws on the Cheng Xiang (2018) system construction method to construct the Fintech Policy Index (FPI). The specific steps are as follows:

First, statistics on the text of the Fintech policy: The text of the Fintech policy is the data collection object of this study, and the scope of collection is the policy related to Fintech issued by all government departments separately or jointly. Then, we use the "Chinese Law Search System" to set up 12 full-text search terms such as "Fintech", "Technology Innovation", "Technology Loan", and "Risk Investment" as the full-text search term, from 2010-2017. The year is searched. After screening and eliminating the collected policies, the total number of Fintech policies that were finally included in the study sample was 84,400 .

Second, the analysis of the keywords of the policy text: This paper analyzes the keywords of the Fintech policy, each policy has one to three related keywords, summed up the "strategic planning", "technical loans" etc.12 keywords in total.

Third, the construction of FPI: We quantify the 12 key word frequency proposed in the previous article and determine the number of factors by means of factor analysis. According to the feature root is greater than 1, and the $\mathrm{KMO}$ test result is greater than 0.5 , the factor is determined: technical support. In addition, since this paper focuses on the Fintech policy for private enterprise financing, the other two Fintech policy indicators are: loan financing, channel business. Table 1 shows the three major factors classified by financial function summarized in this paper, a total of 12 . 
Table 1. Factor composition

\begin{tabular}{|c|c|c|c|c|c|}
\hline $\begin{array}{l}\text { Financial } \\
\text { Function }\end{array}$ & \multicolumn{5}{|c|}{ Key words of Fintech Policy } \\
\hline Loan Financing & \multicolumn{2}{|l|}{ Fintech Loan } & Risk Investment & Financial Lease & Credit System \\
\hline Channel Service & \multicolumn{2}{|l|}{ Strategic Planning } & Fintech Insurance & Fintech Industry & Fintech Enterprise \\
\hline \multirow{2}{*}{ Technical Support } & Scientific & Technological & Information & Achievement & Comprehensive \\
\hline & Guarantee & & Sharing & Transformation & Type \\
\hline
\end{tabular}

We use regression analysis to estimate the score coefficient matrix of the factor and calculate the factor score. The Fintech Policy Index (FPI) weights the factor scores and represents the common factors as a linear combination of the original variables. We use the principle of maximum minimization to normalize each data to $0 \sim 1$, and standardize each factor and synthetic index $0-1$, using the formula as follows:

$$
\frac{x-\min (x)}{\max (x)-\min (x)}
$$

Get 2010-2017 Fintech Policy Index in table2.

Table 2. 2010-2017 Fintech Policy Index FPI

\begin{tabular}{lllll}
\hline Year & Loan Financing & Channel Service & Technical Support & FPI \\
\hline 2010 & 0.31398 & 0.59337 & 0.39466 & 0.43400 \\
2011 & 0.34444 & 0.54018 & 0.37645 & 0.42034 \\
2012 & 0.36137 & 0.54646 & 0.37998 & 0.42927 \\
2013 & 0.34910 & 0.55922 & 0.35825 & 0.42219 \\
2014 & 0.35864 & 0.60010 & 0.34448 & 0.43440 \\
2015 & 0.30126 & 0.41052 & 0.32220 & 0.35799 \\
2016 & 0.33388 & 0.43890 & 0.33347 & 0.37541 \\
2017 & 0.32964 & 0.51797 & 0.32940 & 0.39234 \\
\hline
\end{tabular}

Table 2 shows that during 2010-2017, the FPI showed obvious phase characteristics, specifically:

In 2010-2014, the FPI index and the corresponding lending financing index showed a steady state. At this stage, Fintech is in a period of rapid development, the relevant risks have not been exposed, and the government encourages the development of Fintech;

In 2014-2015, the FPI index showed a downward trend. At this stage, as the risks of Fintech gradually emerged, both the FPI and the loan financing index have declined;

In 2015-2017, with the introduction of relevant laws and the implementation of regulatory bodies, the macro-development of Fintech has once again increased.

\subsection{Construct Index of FI}

This paper draws on the system construction method of Liu Yuan (2018) to construct the Fintech Index (FI). The specific steps are as follows:

Firstly, using word extraction and Baidu search engine, quantify the original vocabulary to calculate the keyword frequency of Fintech, and determine the number of factors by means of factor analysis; secondly, according to the feature root greater than 1 , and the KMO test result is greater than 0.5 , the technical support factor is determined; in addition, since the text focuses on the Fintech to the private enterprises' financing field, the other two Fintech index is: loan financing, channel business. This makes the index more targeted. Table 3 shows the three major factors classified by financial function summarized in this paper, a total of 15 . 
Table 3. Factor composition

\begin{tabular}{llllll}
\hline Financial Function & \multicolumn{1}{l}{ Key Words of Fintech } & & & \\
\hline Loan Financing & Net Loan & Crowd-Funding & Network Loan & Online Financing & Online Investment \\
Channel Service & Electronic Bank & Online Banking & Net Silver & Network Bank & Mobile Banking Service \\
Technical Support & Big Data & Cloud Computing & Artificial Intelligence & Block Chain & ABS Cloud \\
\hline
\end{tabular}

Secondly, the Fintech Index (FI) takes the factor score as a weight and expresses the common factor as a linear combination of the original variables, and normalizes each data to $0 \sim 1$, using the principle of maximum minimization, respectively, and the respective factors and synthetic indices. Perform 0-1 standardization, using the same formula (1) as mentioned before.

Get 2010-2017 Fintech index (FI) shown in the table 4.

Table 4. 2010-2017 annual Fintech index

\begin{tabular}{lllll}
\hline Year & Loan Financing & Channel Service & Technical Support & Fintech Index \\
\hline 2010 & 0.23008 & 0.73764 & 0.22745 & 0.38156 \\
2011 & 0.21942 & 0.42492 & 0.22855 & 0.28381 \\
2012 & 0.21494 & 0.73949 & 0.23782 & 0.37917 \\
2013 & 0.23119 & 0.47983 & 0.23102 & 0.30575 \\
2014 & 0.27608 & 0.23181 & 0.27245 & 0.25955 \\
2015 & 0.21812 & 0.45440 & 0.24043 & 0.29569 \\
2016 & 0.23385 & 0.47419 & 0.23247 & 0.30554 \\
2017 & 0.33182 & 0.79686 & 0.24441 & 0.44511 \\
\hline
\end{tabular}

Table4 displays that in 2010-2017 Fintech Index (FI) shows a fluctuating upward trend. More specifically:

In 2010-2013, Fintech was in a period of rapid development and risk accumulation, and both FI and lending financing index showed an unsteady trend;

In 2013-2015, after the rapid development and risk accumulation in the early stage, Fintech gradually showed its defects. At this stage, both the FI and the loan financing index have declined;

In 2015-2017, with the introduction of relevant policies, the comprehensive combination of Fintech and financial supervision made the Fintech index rise steadily.

\subsection{Apply the Time-Varying Parameter State Space Model}

This paper is going to use the Time-Varying Parameter State Space Model to measure the degree of private enterprises' financing:

$$
y_{t}=\beta_{t} x_{t}+\mu_{t}
$$

$y_{t}$ is the dependent variable, $x_{t}$ is the variable vector, $\beta$ is estimated $\mathrm{m} \times 1$ unknown parameter vector, $\mu_{t}$ is disturbing term. Regression model is as follows:

$$
y_{t}=\beta_{t} x_{t}+z_{t} y+\mu_{t} \mathrm{t}=1,2,3 \ldots \mathrm{T}
$$

$\beta_{t}$ is Variable Parameter, get the Time Series Model AR(p), which is described as:

$$
\beta_{t}=\varphi \beta_{t-1}+\xi_{t}+\mu_{t}
$$

Plus, assumption $\left(\mu_{t}, \xi_{t}\right)^{\prime} \sim N\left[\left[\begin{array}{l}0 \\ 0\end{array}\right],\left[\begin{array}{cc}\sigma_{t}^{2} & g \\ g & Q\end{array}\right]\right] \mathrm{t}=1,2,3 \ldots \mathrm{T}$

Neither $\mu_{t}$ nor $\xi_{t}$ are necessarily independent of each other, but from the average value of 0 , the variance is $\sigma_{t}^{2}$ of the normal distribution.

\subsection{Do the Empirical Analysis and Test}

This paper selects the annual data of 96 private enterprises in Jiangsu Province that are well-operated in 2010-2017 as a sample of research and selects bank loans in indirect financing as a proxy variable for measuring the financing level of private enterprises (y). The data comes from WIND Database. All continuous variables are treated with $1 \%$ tail processing. The FPI, which was constructed through the previous article, was chosen as the 
macro level of the degree of development of Fintech (x1). The Fintech index FI, which was constructed by the above, was chosen as the micro level of the degree of development of Fintech (x2).

\subsubsection{Data Preprocessing}

$\mathrm{y}, \mathrm{x} 1$, and $\mathrm{x} 2$ belong to time series data, logarithm them to eliminate heteroscedasticity and perform unit root test:

Table 5. Unit Root Test of correlation sequences

\begin{tabular}{cllllll}
\hline $\begin{array}{c}\text { Primary } \\
\text { sequence }\end{array}$ & $\begin{array}{l}\text { Inspection } \\
\text { form }\end{array}$ & ADF Value & $\begin{array}{l}\text { Critical Value } \\
\mathbf{( 1 \% )}\end{array}$ & $\begin{array}{l}\text { Critical Value } \\
\mathbf{( 5 \% )}\end{array}$ & $\begin{array}{l}\text { Critical Value } \\
\mathbf{( 1 0 \% )}\end{array}$ & P Value \\
\hline $\ln \mathbf{y}$ & $(\mathrm{c}, \mathrm{t}, 3)$ & -0.6422 & -2.18364 & -1.20134 & -1.62383 & 0.8192 \\
$\Delta \ln \mathbf{y}$ & $(\mathrm{c}, \mathrm{t}, 3)$ & -3.9383 & -2.23845 & -2.03923 & -1.18233 & 0.0628 \\
$\ln \boldsymbol{x}_{\mathbf{1}}$ & $(\mathrm{c}, \mathrm{t}, 3)$ & -0.1829 & -3.03928 & -2.33820 & -1.02936 & 0.9921 \\
$\Delta \ln \boldsymbol{x}_{\mathbf{1}}$ & $(\mathrm{c}, \mathrm{t}, 3)$ & -3.3403 & -1.19304 & -2.03848 & -1.92849 & 0.0989 \\
$\ln \boldsymbol{x}_{\mathbf{2}}$ & $(\mathrm{c}, \mathrm{t}, 3)$ & -0.6028 & -3.38493 & -2.13921 & -1.65200 & 0.9302 \\
$\Delta \ln \boldsymbol{x}_{\mathbf{2}}$ & $(\mathrm{c}, \mathrm{t}, 3)$ & -3.3836 & -3.29384 & -1.91837 & -1.70425 & 0.0839 \\
\hline
\end{tabular}

The unit root test analysis shows that there is a long-term stable equilibrium relationship between FPI and FI on the development of private enterprises in China.

\subsubsection{Model Setting}

A variable parameter space state model for establishing the Fintech policy index and the pulling effect of the Fintech index on private enterprise financing:

Measuring Equation:

$$
y_{t}=\pi+\alpha_{t} x_{1 t}+\beta_{t} x_{2 t}+\mu_{t}
$$

State Equation:

$$
\left\{\begin{array}{l}
\alpha_{t}=\alpha_{t-1} \\
\beta_{t}=\beta_{t-1} \\
\gamma_{t}=\gamma_{t-1}
\end{array}\right.
$$

In the definition of variable parameter model, the variable parameter model proposed by Pan Xiongfeng (2012), which is defined as:

$$
\begin{gathered}
\text { @singal lny }=\mathrm{c}(1)+\mathrm{sv} 1 * \ln \mathrm{x} 1+\mathrm{sv} 2 * \ln \mathrm{x} 2+[\operatorname{var}=\exp (\mathrm{c}(2))] \\
@ \text { state sv1 }=\operatorname{sv} 1(-1) \\
\text { @state sv2 }=\operatorname{sv} 2(-1)
\end{gathered}
$$

\section{Results}

\subsection{Model Operation and Result Analysis}

The results of the variable parameter space state model calculated by Eviews8.0 software are shown in Table 6 .

Table 6. Estimation and test of Time-Varying parameter model parameters

\begin{tabular}{lllll}
\hline Parameters & Coefficient & Std. Error & z- Statistic & Prob. \\
\hline C(1) & 2.708709 & 0.772308 & 2.983930 & 0.0001 \\
C(2) & -2.278178 & 0.351808 & -7.178393 & 0.0000 \\
parameter & Final Stat & Root MSE & z-Statistic & Prob. \\
SV1 & 1.836292 & 0.061879 & 18.22830 & 0.0000 \\
SV2 & 0.345618 & 0.102505 & 2.305661 & 0.0000 \\
\hline
\end{tabular}

It could be seen from Table 6 that the $\mathrm{p}$ values are all tested, so the model selection is correct. The following is a detailed analysis of the State Space Model:

(1) Elastic analysis of the Fintech policy index on the development of private enterprise financing. 


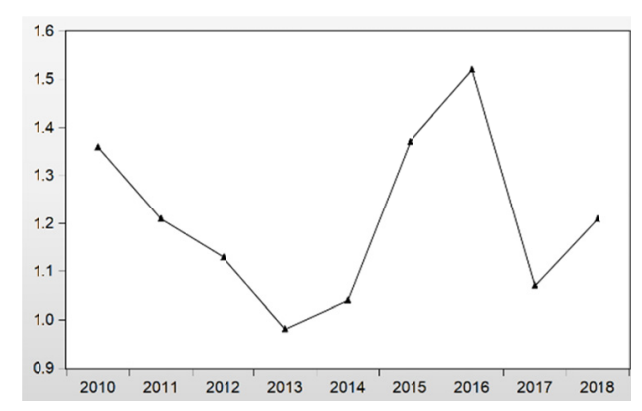

Figure 1. The elasticity coefficient of the Fintech policy index on the financing devellopment of private enterprises

It could be seen from the graph that the Fintech policy index has obvious stage characteristics for the development of private enterprises' financing, and basically presents a W-type trend. The initial value of this paper is selected from 2010, and the elasticity coefficient of its Fintech policy index for private enterprises' financing is 1.36 .

2010-2013: In 2010, private enterprises' internal information is not transparent, and commercial banks have strict loan access system, leading to private enterprises' financing difficulties. Although the Fintech in this stage has experienced a period of rapid development, the Fintech policy itself has a certain lag effect. In addition, P2P Borrowing and getting caught up in a money laundering trap, into a debt service crisis, which made some private enterprises fell. Most banks have taken a contractionary approach to their balance sheets and had strictly controlled loan access threshold. In this situation, 2013, reached the maximum degree of reflection in the year, so in the 2013 the Fintech policy index has almost no effect on the financing situation of private enterprises, reaching the first trough of "W".

2013-2016: With the development of the Fintech, the elastic coefficient of the FPI to private enterprises has been improved continuously, and in 2016, it reached the first peak of "W" Type.

In 2016, with the promulgation of the National Fintech Innovation Plan of the Thirteenth Five-Year Plan, State More clearly, the Fintech, the subject of supervision and risk control were stated out. On the one hand, the network loan from the government increases the financing cost of the private enterprises; on the other hand, after a large-scale crackdown, the mandatory closure of online lending platforms, which does not comply with the relevant laws and policies, has reduced the financing channels of private enterprises to some extent. Therefore, in the 2016-2017, the elasticity coefficient of Fintech Policy Index to Private Enterprises' financing shows a downward trend.

In 2018, President Xi Jinping proposed the "125 Plan" to help private enterprises to raise funds. FPI and the financing situation of Private Enterprises will rise simultaneously. So, the correlation coefficient will rise.

(2) Elastic analysis of Fintech index to private enterprises' financing.

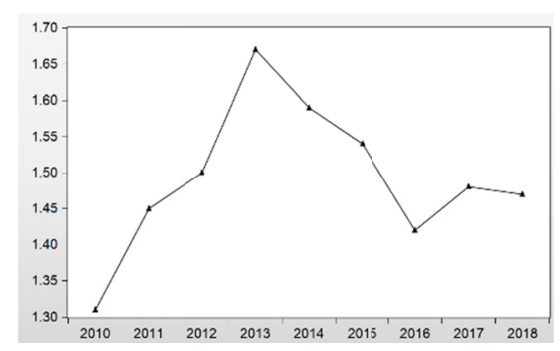

Figure 2. The elasticity coefficient of the Fintech index on the financing development of private enterprises

Figure 2 shows that the coefficient of elasticity of the FinTech Index for private enterprises' financing development also shows a phased development trend.

Before 2013, it was the risk accumulation period of Fintech. At this stage, the negative effects of Fintech risks 
have not yet been shown. The impact of the FinTech Index on the financing efficiency of private enterprises has gradually increased and reached its first peak in 2013. The main performance is that Fintech has broadened the financing channels for private enterprises, giving private enterprises the opportunity to finance from Internet financial institutions and reduce private ownership. Transaction costs of the company in the financing process.

After 2013, the Fintech risks erupt. During this time, many financial institutions, like shadow banks, went bankrupt and collapsed. At the same time, shadow banking and other online lending platforms close, which makes private enterprise oneself safety coefficient drops.

In 2016, CBRC issued interim measures for the Management of Business activities in Network Lending Information intermediaries, which opened the comprehensive supervision of Fintech. Based on this, the elastic coefficient of Fintech Index for private enterprises is rising step by step.

At present, the elastic coefficient of Fintech Index to the financing situation of private enterprises in China is in a rising stage of "W".

\section{Discussion}

This paper applies the State Space Model using data from 2010 to 2017 to demonstrate the relationship between the Fintech Index, Fintech Policy Index and the private enterprises' financing, the result shows that:

The elasticity between the Fintech Policy Index and private enterprise financing is developed as "W" trend,

2010-2013: In 2010, the FPI showed a downward trend to private enterprises' financing.

2013-2016: In 2013, the FPI to private enterprises' financing showed a rapid upward trend to the financing elasticity coefficient and during 2016-2017, the trend went down again.

2017-2018: The elastic coefficient of the relationship between the two is rising again.

The elasticity of Fintech Index to private enterprise financing is developed as "W" trend:

2010-2013: In 2010, the elasticity coefficient of FI to private enterprise financing showed a rapid rising trend.

2013-2016: In 2013, the FI showed a rapid downward trend to the development of private enterprises' financing.

2016-2017: The FI once again shows a small upward trend to private enterprises' financing.

The relationship between Fintech and private enterprises' financing could be obtained by synthesizing the development of Fintech at macro and micro level, and the relationship between Fintech and private enterprises' financing could be obtained "W" type a trend. At present, Fintech could promote the development of private enterprises' financing.

In view of this periodic change, this paper puts forward the following policy suggestions:

Firstly, the government should strengthen the support for the directed development of Fintech, giving full play to the role of the government in mobilizing financial funds, and make use of the Fintech policy to guide private enterprises' financing.

Secondly, the government should speed up the implementation of Fintech Policy. Through the establishment of provincial and municipal government Fintech policies to promote the development of private enterprise financing performance goals, further reduce the policy lag effect, timely and effectively to help private enterprises out of the financing difficulties.

Finally, the government should further strengthen the supervision of Fintech and improve relevant laws and regulations in the process of implementing Fintech policy. Minimize the high leverage risk of Fintech, and ensure that network security, data security and privacy protection throughout the development of Fintech, thereby gradually smelting the volatility of Fintech, and playing the role of Fintech in financing private enterprises to guide.

\section{References}

Wen, X. Z., \& Zhang, J. (2006). An Analysis of the Deep causes of the difficulty in financing Private small and Medium-sized Enterprises in China. Business Studies, (10), 146-147. https://doi.org/10.13902/j.cnki.syyj.2006.10.043

Zhang, W. L., Gao, Q., \& Zhang, P. Y. (2018). Small Micro enterprise Analysis of the causes of the difficulty in financing and the Countermeasures to solve it. Modern Commerce and Industry, 39(34), 103-104. https://doi.org/10.19311/j.cnki.1672-3198.2018.34.061

Li, J., \& Zhang, Y. S. (2015). Analysis of P2P Mode of Private economy financing. Journal of Shenyang 
Institute of Engineering (Social Sciences $\quad$ Edition), $11(3), \quad 332-336$. https://doi.org/10.13888/j.cnki.jsie(ss).2015.03.011

Zhao, H. (2016). Characteristics, rise, function and risk of Fintech. Research on Financial Supervision, (9), 57-70. https://doi.org/10.13490/j.cnki.frr.2016.09.004

Liu, Y., Zheng, J. Y., Jiang, P., \& Liu, C. (2018). Does Fintech help to improve the efficiency of investment in the real economy? Journal of Capital University of Economics and Technology, (6), 22-33. https://doi.org/10.13504/j.cnki.issn1008-2700.2018.06.003

Pan, X. F., Shi, X. H., \& Wang, M. (2012). A study on the effects of Fiscal and Financial Policy on the Development of Fintech in China: an Analysis of variable parameters based on State Space Model. Scientific Studies, 30(6), 865-869. https://doi.org/10.16192/j.cnki.1003-2053.2012.06.003

Wang, K., \& Wu, Q. (2018). A study on the impact of Fintech on China's Banking systemic risk. Modernization of Management, 38(3), 112-116. https://doi.org/10.19634/j.cnki.11-1403/c.2018.03.030

Frederic, M., \& Philip, S. (2018). What will technology do to financial structure? Working Paper $6892,9$. https://doi.org/10.1016. https://doi.org/10.1016/j.procs.2018.07.288

Conrad-He, T., \& Schultz, H. B. D. (2015). Comparison of visual recovery and refractive stability between femtosecond laser-assisted cataract surgery and standard phacoemulsification: Six-month follow-up. Journal of Cataract \& Refractive Surgery, 41(7). https://doi.org/10.3386/w6892

Will, S. (2018). Fintech Model: The Random Neural Network with Genetic Algorithm. Procedia Computer Science. https://doi.org/10.1016/j.procs.2018.07.288

\section{Copyrights}

Copyright for this article is retained by the author(s), with first publication rights granted to the journal.

This is an open-access article distributed under the terms and conditions of the Creative Commons Attribution license (http://creativecommons.org/licenses/by/4.0/). 